André Bueno

\title{
Razumeti "novi konfucianizem«: ponovno odkrivanje konfucianizma in prihodnost Kitajske ${ }^{1}$
}

\begin{abstract}
Ključne besede: kitajska filozofija, novi konfucianizem, religija, politika, družbene
\end{abstract} doktrine

DOI: 10.4312/ars.10.1.209-219

\section{Uvod: cerkev v Qufuju}

Leto 2010 je zaznamovala vroča razprava v povezavi z mestom Qufu 曲阜, rojstnim krajem modrega Konfucija. Napoved gradnje nove krščanske cerkve v bližini Konfucijevega templja je sprožila vihar med novimi kitajskimi konfucianisti. Načrt za skoraj štirideset metrov visoko katedralo v zahodnjaškem stilu, ki bi lahko sprejela tri tisočljudi (skoraj vso krščansko skupnost mesta, ki je po »nenavadnem «naključju enaka številu Konfucijevih učencev), bi posegel v arhitekturno podobo mesta. Nelagodje je bilo vsesplošno, saj bi stavba take velikosti neposredno ogrozila arhitektonski kompleks treh konfucijskih poslopij, ki so del svetovne dediščine UNESCO. Odziv je bil hiter in oster: pismo oziroma manifest, ki so ga podpisali najpomembnejši sodobni konfucijanski misleci, je mestne oblasti prisililo, da so gradnjo ustavile in načrtovanje nove cerkvene zgradbe prestavile za nedoločen čas.

Na podoben način je bilo leto 2010 zanimivo za svetovno kinematografijo. V skoraj vseh državah sveta je znanstvenofantastični film Avatar požel velikanski uspeh, ne pa tudi na Kitajskem, kjer ga je po prodaji vstopnic presegel epski spektakel z izjemno scenografijo, biografija o Konfuciju, ki ga je upodobil Chow Yun-Fat 周潤發.

Ta dva dogodka precej nazorno kažeta na pomembno spremembo v sodobni kitajski misli: ponovno rojstvo konfucianizma kot moralne, filozofske in politične poti. Nekaj let prej bi bila taka stališča za veliko večino Kitajcev nepredstavljiva (ali celo nerazumljiva). Na konfucijanskih stavbah v Qufuju so še vedno vidne poškodbe kulturne revolucije (1966-1969). Poleg tega pa kljub številnim poskusom, da bi konfucianizem v dolgem maoističnem obdobju (1949-1976) prepovedali, starodavni

1 Pričujoči članek je bil prvič objavljen leta 2015 v španski znanstveni reviji Ámbitos. Revista de estudios de ciencias sociales y humanidades, 33, str. 117-121. 
nauk izobražencev $\mathrm{v}$ sedanji kitajski družbeni panorami ponovno dobiva moč in postaja pomembna politična opcija za prihodnost.

$\mathrm{V}$ tej kratki študiji bomo poskusili osvetliti nekaj vidikov ponovnega rojstva konfucianizma $\mathrm{v}$ moderni kitajski družbi ter razumeti možne posledice in vplive. Študija temelji predvsem na delih misleca Jiang Qinga 蒋庆, ${ }^{2}$ enega najbolj razvpitih ideologov t. i. »novega konfucianizma«, ter na delih njegovega glavnega zahodnega interpreta, raziskovalca Daniela Bella.

\section{Konfucianizem: "problem Zahoda«}

Da bi bolje razumeli prebujanje novega zanimanja za konfucianizem, imenovan Xin Rujia 新儒家 (nekaj takega kot »novi konfucianizem «), ${ }^{3}$ moramo najprej razumeti sam konfucianizem kot intelektualno gibanje - in od tod izhaja največja težava zahodnih mislecev.

Splošno gledano, evropocentrična težnja po kategoričnem klasificiranju različnih oblik razmišljanja glede konfucianizma nikoli ni dosegla konsenza. Pogosto je bil nauk izobražencev klasificiran kot "religija «, čeprav se ga nikoli ni uspelo umestiti $\mathrm{v}$ to tipologijo. $\mathrm{K}$ tej intelektualni oviri je pripomoglo tudi sistematično zavračanje zahodnih filozofov kateregakoli azijskega razmišljanja kot »filozofije«. Na koncu je treba omeniti še sociologijo, ki na konfucianizem gleda kot na oddaljeno ideološko in politično formo, vendar ne da bi natanko poznala njegov zgodovinski okvir.

Jasno je, da so te ovire lastne zahodnim mislecem. Klasifikacije, ki naj bi predpostavljale tudi raziskovalni okvir, so nejasne in zavajajoče, medtem ko proučevanje izvornega konfucianizma pokaže, da je obsežnejši in zapletenejši od okvirov, ki jih dovoljujejo naše kategorizacije. Kakorkoli, zanimiv vidik tega »novega konfucianizma« je dejstvo, da ponuja odgovore na nekatera omenjena vprašanja, kar implicira pomembno in obsežno spremembo v »kitajskem načinu razmišljanja«, ki jo je sprožila »zahodna misel«. Zato se zdi legitimno »novi konfucianizem« poskusiti analizirati $z$ dvema različnima pristopoma: najprej ga dekonstruirati in nato opazovati razsežnost njegovega programa.

2 Jiang Qing, Zhengzhi Ruxue (Politični konfucianizem), Yucheng, 1991 (2003).

3 Ali tudi "postkonfucianizem« (v slovenskem prostoru je za to gibanje uveljavljen izraz »moderno konfucijanstvo«, op. prev.), s čimer se izognemo zamenjavi s terminom »neokonfucianizem«, ki označuje široko gibanje reforme konfucianizma v obdobjih Song 宋 (960-1279) in Ming 明 (13681644), v kitajščini Song Ming Lixue 宋明理学. V tem dolgem obdobju ponovnega proučevanja konfucianizma se je oblikovala serija briljantnih mislecev ne samo na Kitajskem, temveč tudi na Japonskem, v Koreji in Vietnamu. 


\section{3 »Novi konfucianizem« kot religija}

Od Konfucija 孔子 (551-479 pr. n. št.) naprej se konfucianisti nikoli niso ukvarjali s teološkimi vprašanji. Metafizične raziskave, s katerimi so se ukvarjali misleci obdobja Song 宋 in Ming 明, ${ }^{4}$ so temeljile bolj na kozmologiji kot na verovanju v božanstva. Nekatere vidike konfucianizma, na primer prakso žrtvovanja prednikom in priznavanje Neba (Tian 天) kot superiorne inteligence, bi sicer lahko opredelili kot religiozne, saj bi lahko nakazovali na obstoj določene veroizpovedi. Pa vendar lahko sam kult žrtvovanja prednikom razumemo kot nekaj simbolnega, medtem ko lahko konceptualizacijo Neba preprosto beremo kot ekološki razlog za obstoj (ali kot »naravne zakone«). ${ }^{5}$ Branje Liji 礼, temeljnega besedila o starih konfucijanskih družbenih pravilih, to tudi dokazuje: gre za jasno izraženo skrb za življenje v družbi, skupaj z običaji in praksami.

Prevod besede $L i$ kot »ritual«, ki sta ga vpeljala verska misleca, prevajalca in razširjevalca konfucijske misli v Evropi, James Legge (1815-1897) in Seraphim Couvreur (1835-1919), je močno zaznamoval nadaljnje razumevanje tega koncepta, ki bi ga lahko prevedli kot »navada«, »družbene norme«, "kulturne norme« itd. Zaradi tega razloga je raba termina »religija « skupaj s konfucianizmom sprožila določene probleme, na primer, kako je lahko konfucianizem religija, če pa nima duhovščine? Poleg tega je konfucianizem postavil osnove za obširen izobraževalni in moralni nauk, do katerega so imeli s študijem dostop vsi Kitajci. Torej so na neki način vsi Kitajci »konfucijanci«. Vendar pa je teh več tisoč učencev lahko imelo vsak svoje metafizično verovanje (budistično, daoistično, islamsko, krščansko itd.), kar ovrže opredelitev konfucianizma kot možne religije. Konfucijski intelektualci so bili učitelji, misleci, filozofi, zato o konfucianizmu nimamo razloga razmišljati kot o obliki religije.

Polemika v Qufuju leta 2010 pa razkriva še en obraz »novega konfucianizma«. Jiang Qing, eden vodilnih mislecev tega gibanja in eden avtorjev manifesta ${ }^{6}$ proti gradnji krščanske cerkve, predlaga, da "novi konfucianizem« razumemo kot novo obliko religije, in sicer kot neke vrste nacionalistični kitajski humanizem, ki bi bil neodvisen od božanstev, vendar pa bi se osredotočal na predanost človeku. V svojih argumentih proti gradnji krščanske cerkve v Qufuju kritiko oblikuje v dveh smereh: prva je poziv k ohranjanju svetovno priznane umetniške in kulturne dediščine, druga pa se sklicuje

4 Glej prejšnjo opombo.

5 Glede odnosa med konfucianizmom in ekologijo glej Berthrong, J., Tucker, M., Confucionism and Ecology, Harvard 1998.

6 Manifest $\mathrm{z}$ naslovom 尊重中华文化圣地, 停建曲阜耶教教堂-关于曲阜建造耶教大教堂的意见 书 je dostopen na spletni strani: http://www.kong.org.cn/bbs2/a/a.asp?b=2\&id=85852. 
na vprašanje ohranjanja kitajske kulturne identitete, ki bi jo tâki religiozni vplivi lahko ogrožali. Jiang tako prevzame argumentacijo, ki jo je v obdobju Tang 唐 (618-907) uporabil že Hanyu 韓愈 (768-824) v svoji kritiki prodora budizma na Kitajsko. Če lahko določena religija spremeni družbene običaje in prakse, to pomeni, da je lahko ogrožen tudi obstoj kulture. Čeprav vemo, da se kulture nenehno spreminjajo, je vzdrževanje »kitajske identitete« pravzaprav smiselno v starodavni civilizaciji, katere večtisočletni obstoj je predvsem posledica ohranjanja kulturnega pomena ter intimne in neločljive povezanosti s preteklostjo. Zato bi morala biti Konfucijeva moralna načela upoštevana kot množica življenjskih pravil, ki jim izkazujemo predanost, brez tega bi bilo njihovo izvajanje manj učinkovito ali celo neuporabno. $\mathrm{V}$ takih primerih $\mathrm{v}$ kitajski zgodovini prihaja do kriznih trenutkov, njihov prvi pokazatelj pa je družbena in duhovna napetost. ${ }^{7}$

Verjetno je, da si Jiang Qing prizadeva nasloviti vztrajanje Zahoda po opredelitvi konfucianizma kot religije. Vse od prihoda krščanskih misijonarjev v 16. stoletju je bila konfucijanska misel obravnavana kot oblika pobožnosti, kar razkriva nezmožnost zahodnega človeka razumeti, da lahko določen nauk preživi toliko stoletij, ne da bi bil »religija«, tako kot na primer judaizem, krščanstvo ali islam. Leta 1979 izdano delo Kitajska in krščanstvo, ki ga je uredil Leonardo Boff, predstavlja zbirko analiz različnih mislecev o vprašanju religije na Kitajskem ter o možnem dialogu med Kitajsko in krščanstvom. ${ }^{8}$ Čeprav je delo pomenilo velik korak naprej glede terminologije medkulturnih konceptov, ga še vedno zaznamuje razumevanje, da lahko v kitajsko dejanskost prodremo samo skozi religiozno misel. ${ }^{9}$ In tâko prepričanje je aktualno še dandanes. Z nadaljevanjem kitajske rasti v 21. stoletju se je skrb zaradi »spreobrnjenja« Kitajske v krščanstvo eksponentno povečala, kot je razvidno tudi iz dogodka v mestu Qufu. Poleg tega prihaja do postopnega upadanja marksističnih vladnih teorij, zato je povsem mogoče, da se bo ideološka praznina zapolnila $\mathrm{z}$ religioznimi teorijami, za katerimi stojijo močno aktivne politične skupine, kot se je zgodilo v nekaterih zahodnih državah, tudi v Braziliji. Jiang Qingova skrb se zato zdi relevantna, čeprav bi se ob njegovem predlogu, naj konfucianizem postane religiozno gibanje, verjetno zgrozil sam Konfucij, ki si je vselej prizadeval za avtonomne in kritične posameznike. Toda religija brez bogov, katere nauk je praksa harmoničnih družbenih navad, se zdi priročna $\mathrm{v}$ povsem možnem postmarksističnem obdobju (Ping, 2011, 163-185).

7 Podrobnejšo obravnavo tega vprašanja predstavlja knjiga Yong Chena Confucianism as religion: Controversies and Consequences. Leiden, Brill, 2013. V zadnjem delu Yong natančno pretrese Jiangovo prizadevanje za transformiranje konfucianizma v religijo. Boff, L. (ur.), China e Cristianismo, Petrópolis 1979.

9 Članek iz omenjene knjige, ki je v povezavi s to temo še posebej poučen, je »Kitajska kultura skozi zahodni pogled «, avtor je Shao Yuming 邵玉銘. 


\section{Politični »novi konfucianizem«}

Vendar pa je projekt Jiang Qinga (1991 [2003]) dosti širši, saj v prihodnosti Kitajske konfucianizem vidi kot najverjetnejšo zamenjavo za marksizem. Toda če je konfucianizem politični in družbeni nauk, ki se je uveljavil v obdobju cesarskih dinastij, se za Kitajce ne zdi, da bi se radi vrnili v tisto obdobje. Kako torej narediti, da bi se osrednje Konfucijeve vrednote, kot so meritokracija, politična etika in sistem družbenih dolžnosti, obdržale in vključile v nov politični sistem? Jiang Qing se za rešitev tega vprašanja ponovno sklicuje na uvoz zahodnega modela, republike (Bell, 2012).

Lahko rečemo, da je imela Kitajska pomembno izkušnjo s komunističnim republikanskim sistemom, ki je vzpostavil državo po težkem zgodovinskem obdobju od druge polovice 19. do prve polovice 20. stoletja. Padec cesarstva ni bil samo zgodovinski šok, temveč je hkrati ponudil priložnost za obnovo, ki so jo Kitajci dobro izkoristili, čeprav so obdržali birokratsko tradicijo, ki je očitno bistvena za vodenje države takih dimenzij. Komunistična partija pa je ostala edina možnost za udeležbo v političnem življenju. Jiang zato predlaga, da se obdrži participativno republiko, organizirano v tri ločene skupščine, ki predstavljajo vse različne družbene segmente. Ena od pomembnih značilnosti takega sistema je obstoj glavne skupščine, v katero bi se lahko vključili posamezniki s trdno administrativno kariero, ki bi opravili javne izpite. Ta skupščina bi tako vsebovala kitajsko intelektualno elito in bi imela primarno pristojnost odločanja.

Jiangov predlog analizira Daniel Bell $(2008,2011)$ in ugotovi dve zanimivi podrobnosti: najprej, da ta predlog krepi že obstoječo težnjo v sodobni Kitajski po oblikovanju političnih kadrov s tehniki in specialisti. Skoraj $75 \%$ aktualnih voditeljev je visoko usposobljenih profesionalcev na svojih področjih, kar naj bi bil eden izmed razlogov za gospodarski uspeh Kitajske. Po drugi strani bi se pri oblikovanju tega sistema izpolnili tudi dve osnovni značilnosti tradicionalne kitajske politične mentalitete: krepitev meritokracije in slabitev demokracije. Čeprav bi to lahko bila večstrankarska republika, bi glavne odločitve še vedno sprejemala elita, v katero bi se lahko vstopalo na podlagi intelektualnih sposobnosti ali uspeha na sprejemnih izpitih. Jasno je torej, da je v tem primeru možnost odločanja $\mathrm{z}$ demokratičnim glasovanjem (neposrednim ali posrednim) na najvišjih družbenih ravneh praktično izključena. Znotraj »kitajskega konfucijanskega načina razmišljanja« bi bil Jiang Qingov predlog smiseln: konec koncev se zdi grozljivo, da bi pomembne državne odločitve lahko sprejemala nekvalificirana oseba. Vendar pa idealni Jiangov sistem ne upošteva dveh osnovnih problemov. Prvi je, da se lahko na javnih izpitih goljufa (kar se je že dogajalo v kitajskem cesarstvu), s čimer na oblast pridejo posamezniki z dvomljivimi 
sposobnostmi za vladanje. Finančno močne družine ali širše skupnosti bi lahko z vplivanjem na potek javnih natečajev tako zaobšle sistem. Podobno je predpostavka, da so izobraženci tudi značajsko dobri, da jih skrbi za družbo ter da so poznavalci humanističnih načel, ena izmed nerešljivih šibkosti konfucijskega nauka. Sam Konfucij je imel težave $\mathrm{z}$ lenimi in značajsko slabimi učenci. Kako torej predpostavljati, da danes teh težav ne bi bilo več?

Jedro problema je, da se zdi vse bolj anahronistično ohranjati komunistični diskurz v gospodarski dejanskosti nove Kitajske. Njen sedanji razvoj je tesno povezan s postopnimi spremembami kitajske politične panorame in verjetno bo treba v bližnji prihodnosti spremeniti določene značilnosti sistema, da bi se ohranil kontinuiran razvoj države (Mitter, 2011). Vendar pa kitajski marksizem ni samo politični diskurz, temveč ima tudi družbeni in moralni značaj ter je kot tak nadomestil kulturo stare cesarske Kitajske. Če torej ta ideologija izgine, kaj jo lahko nadomesti? Ponovno se zdi, da bi bil to lahko »novi konfucianizem«.

\section{5 »Novi konfucianizem« kot družbena doktrina}

Ponovno se lahko vprašamo, kateri del konfucijanske mentalitete je izginil iz kitajske družbene stvarnosti v obdobju, ko ji je tako srdito nasprotoval Mao Zedong 毛泽东. Strast do študija, vera v delo, ki bo poplačano, predanost učenju, pomembnost skupnosti, vse te vrednote so na Kitajskem obstajale že pred prihodom komunizma ter se nadaljujejo tudi v času maoizma in po njem.

Vendar pa so bile tudi v času maoizma uvedene pomembne družbene reforme. Ostro so nastopili proti moški prevladi in priznali poseben pomen vloge ženske $\mathrm{v}$ družbi, vzpostavljen je bil dostopen izobraževalni in zdravstveni sistem na nacionalni ravni, zagotovljena je bila vrsta socialnih in delavskih pravic, ki so bile Kitajcem do tedaj neznane. Kitajska komunistična država je zagotavljala to široko množico pravic, vendar pa so reforme v času vladavine Deng Xiaopinga 邓小平 (1978-1992) vlado vse manj zavezovale k zagotavljanju teh osnovnih pravic in vse bolj prelagale odgovornost na prebivalce. Po drugi strani pa se je bistveno povečala svoboda izbire pri vlaganju, sodelovanju in samostojnem delovanju na področju trgovine in gospodarstva. Kako torej vzdrževati moralne vrednote, ki zagotavljajo družbeni red, vendar so vse manj javno prisotne, v okolju, ki je vse bolj konkurenčno?

Vrnitev h konfucianizmu se pojavi tako kot zamenjava za občutek brezupa in zapuščenosti, ki so ju s strani države doživeli številni Kitajci. Čeprav je vlada temelj javne uprave, konfucianizem zagovarja aktivno udeležbo posameznika v družbi prek

osebne rasti ter predanosti delu in družini (Madsen, 2010). Življenje v skupnosti bi 
tako temeljilo na sistemu obveznosti do prijateljev, družinskih članov in nadrejenih, ki že od Konfucija temelji na pravicah in dolžnostih vsakega posameznika. Ideološki diskurz na ta način družbene odgovornosti prestavlja na posameznike, tako da ti postanejo aktivni predstavniki družbenega reda. Klasični primer tega je, na primer, koncept »usmiljenja potomcev« (Xiao 孝), ki se pretvori v obveznost otrok, da na starost vzdržujejo svoje starše. Sporen ni sam načrt socialne varnosti, temveč dejstvo, da bo moral moški potomec v državi, kjer ima lahko vsak par samo enega otroka, vzdrževati tako svoje starše kot po vsej verjetnosti tudi starše svoje žene, če ne bo zaposlena. Ekonomsko breme je v teh primerih skoraj neznosno. To je kitajsko vlado nedavno prisililo, da je ponovno razmislila o politiki natalitete.

Konfucianizem se v vsakdanjem življenju ponovno vzpostavlja na različnih ravneh. Kot smo videli, Jiang Qing zagovarja vrnitev k tradicionalnim socialnim vrednotam prek nekakšne religijsko-politične različice konfucianizma. Obstajati namreč mora "verovanje«, da te moralne vrednote služijo ideji višjega družbenega reda, zaradi česar je njihova praksa nujna in nepogrešljiva. Širjenje nauka mora potekati znotraj izobraževalnega sistema skozi proučevanje temeljnih konfucijanskih besedil, kot je na primer Xiaojing 孝经.

Poleg tega velja v tem kontekstu omeniti še nekaj možnosti. Ena izmed njih je raba konfucianizma kot neke vrste samopomoči v vsakdanjem življenju. O tem priča uspeh knjige Konfucij iz srca (Confucius from the heart 论语 “心得, 2006), v kateri avtorica Yu Dan 于丹 uporabi za sodobni svet prilagojene Konfucijeve aforizme kot nasvete, kako se v sodobnem svetu soočati s težavnimi situacijami vsakdana. Načeloma prevladuje mnenje, da tak literarni žanr za kulturno formiranje nima večjega pomena, vendar naj nas to ne zavede. Ta knjiga ima namreč zelo pomembno vlogo, kajti sproži prenos kompleksnejše konfucijanske misli v širšim množicam dostopen »novi konfucianizem«. Tisoče bralcev je pritegnila takšna prilagojena predstavitev s strani državne cenzure odobrenega in "filtriranega « konfucianizma, polnega razmišljanj, ki se postavljajo po robu težavam sodobne družbe. Tako je Yu Danina knjiga postala učinkovit izobraževalni instrument za pripravo bralcev na vrnitev »nauka izobražencev«, da se bodo lahko soočili z dilemami moderne dobe.

\section{Zaključek}

Morda je to eden izmed razlogov, da je bila leta 2010 kitajska javnost pripravljena sprejeti kinematografsko biografijo Konfucija. Mojstrove stiske ter njegovo iskanje pravične politike in idealne družbe so ga ponovno ustoličili kot junaka. Množice so skupaj z izobraženci protestirale proti gradnji megalomanske cerkve v Qufuju in uspele znotraj najpopolnejšega družbenega reda. Projekt, ki ga zagovarja Jiang 
Qing, se zato ne zdi nemogoč, kajti temelji na natančnem opazovanju sprememb v družbenem razvoju. Pod skrbnim nadzorom države, za katero se zdi, da si vse bolj prizadeva, da bi držala korak z ritmom sprememb, kitajska družba postopoma ponovno odkriva konfucijske študije. Branje kitajskih klasikov je sprožilo vrsto novih filozofskih interpretacij, ki so postale središče raziskav predstavnikov »novega konfucianizma « ter jih pripravljajo na soočenje $\mathrm{z}$ družbenimi in političnimi izzivi $\mathrm{v}$ prihodnosti (Makeham, 2003). Lahko torej sklepamo, da ta nauk vključuje raznolike elemente naših običajnih klasifikacij in jih povezuje v enoten sistem, ki si prizadeva, da bi bil »novi konfucianizem« družbeni, politični in morda »religiozni« sistem, kot želijo Jiangovi privrženci.

Dejstvo je, da je konfucianizem kot stara filozofska teorija že močno uveljavljen $\mathrm{v}$ akademskem okolju. Njegova popularizacija v množičnih medijih je poleg tega omogočila široko recepcijo predlogov »novega konfucianizma«, ne da bi bila potrebna kakršnakoli prevzgojna kampanja. Zdi se torej, da se to gibanje razvija povsem spontano, osrednji namen predlogov, ki iz njega izhajajo, pa je zagotoviti jasno usmeritev in ga utrditi. Kako dolgo bo trajalo, da se ta "novi konfucianizem» dokončno uveljavi, ne moremo zagotovo reči. Prav tako je mogoče, da v dinamičnem procesu njegovega formiranja pride do raznolikih modifikacij. Kljub temu pa indici jasno kažejo, da je v prihodnosti Kitajske potrebna nova velika sprememba, ki bo zelo verjetno temeljila na »novem konfucianizmu«.

prevedla Barbara Pihler Ciglič

\section{Literatura}

Bell, D. A., Chainbong, H., Confucianism for the modern world, Cambridge 2003.

Bell, D. A., China's new Confucianism: politics and everyday life in a changing society, Princeton, New Jersey 2008.

Bell, D. A., Confucian Political ethics, Princeton 2010.

Bell, D. A., Jiang Qing's Political Confucianism, v: The Renaissance of Confucianism in Contemporary China (ur. Ruiping, F.), New York 2011, str. 139-152.

Boff, L. (ur.), China e Cristianismo, Petrópolis 1979.

Jiang, Q., Zhengzhi Ruxue 政治儒学 (Confucionismo politico), Yucheng 1991 (2003).

Jiang, Q., Bell, D. A., A Confucian Constitutional Order: How China’s Ancient Past Can Shape Its Political Future, Princeton 2012.

Makeham, J., New confucianism: a critical examination, New York 2003.

Marti, M., A China de Deng Xiaoping, São Paulo 2007. 
Mitter, R., China moderna, Porto Alegre 2011.

Ping-Cheung, L., Jiang Qing on the Inevitable and Permanent Conflict between the Christian Faith and Confucian Culture, v: The Renaissance of Confucianism in Contemporary China (ur. Ruiping, F.), New York 2011, str. 163-185. 
André Bueno

\section{Razumeti "novi konfucianizem«: ponovno odkrivanje konfucianizma in prihodnost Kitajske}

Ključne besede: kitajska filozofija, novi konfucianizem, religija, politika, družbene doktrine

Članek se osredotoči na pomembno spremembo v kitajski misli 20. stoletja: ponovno rojstvo konfucianizma kot intelektualnega gibanja, imenovanega "novi konfucianizem«, ki se v sodobni kitajski družbi ponuja kot možna alternativa marksistični ideologiji. Vendar kaj sploh je »novi konfucianizem«? Avtor najprej izpostavi problematiko poskusa opredelitve konfucianizma $\mathrm{z}$ zahodnega zornega kota in težave, ki se pri tem pojavijo. Opre se predvsem na dela Jiang Qinga 蒋庆, enega osrednjih mislecev tega idejnega gibanja, ter na študije njegovega glavnega zahodnega interpreta, raziskovalca Daniela Bella. V nadaljevanju pretrese nekaj najpogostejših oznak: novi konfucianizem kot religija, kot družbena doktrina ali kot nova politična opcija. Ne glede na neulovljivost koncepta se zdi, da se gibanje v moderni kitajski družbi razvija povsem spontano in pridobiva vse več privržencev, tudi s pomočjo lahkotnejšega literarnega žanra, v katerem se lahko prirejene Konfucijeve misli kot nasveti za soočanje $\mathrm{z}$ vsakdanjim življenjem približajo širši množici. 
André Bueno

\section{Understanding the "New Confucianism": Reinventing Confucianism and the Future of China}

Keywords: Chinese philosophy, New Confucianism, religion, politics, social doctrines

This article focuses on an important change in Chinese thinking of the $20^{\text {th }}$ century: the rebirth of Confucianism as the intellectual movement called "New Confucianism" which is considered in the China of today to be a possible substitute for Marxist ideology. But what exactly is the "New Confucianism"? The author first attempts to highlight the definition of Confucianism from the Western perspective and the problems that arise in that process. The study is based primarily on the work of Jiang Qing 蒋庆, one of the principal thinkers of this movement of ideas, and on the analysis of the main western interpreter of Qing, researcher Daniel Bell. Further along, the paper discusses some of the most common tags of this movement: New Confucianism as a religion, as a social doctrine, and as a new political option for the future. Notwithstanding the elusiveness of the concept it appears to be the case that this movement is developing spontaneously in modern Chinese society and is gaining more and more followers, even via a lighter literary genre through which modified Confucian thoughts and tips for coping with everyday life can approach a wider crowd. 